\title{
Infectious Diseases During the Pandemic COVID-19 in the Republic of Sakha (Yakutia)
}

\author{
Tatyana Dmitriyeva ${ }^{1, *}$, Valentina Grigoryeva ${ }^{2}$, Lyubov Budatsyrenova ${ }^{2}$ and Elena \\ Lytkina $^{2}$ and Vera Egorova ${ }^{1}$ \\ ${ }^{1}$ North-Eastern Federal University named after M.K. Ammosov. 27, Oyunsky St., Yakutsk, 677016, Russia \\ ${ }^{2}$ Russian Federal State Agency for Health and Consumer Rights in the Republic of Sakha (Yakutia), 9, Oyunsky St., \\ Yakutsk, 677027, Russia \\ *Corresponding author. Email: tg.dmitriyeva@s-vfu.ru
}

\begin{abstract}
On the pandemic background of a new coronavirus infection, the widespread anti-epidemic measures, the situation with other infectious diseases has changed. The purpose of this research was to analyze the incidence of infectious diseases in the Republic of Sakha (Yakutia) during 2020 pandemic. We used the data of official statistics. We analyzed the incidence of groups of infectious diseases transmitted by food and air. The incidence of vaccinepreventable diseases was estimated taking into account the level of vaccination of the population. A significant decrease in morbidity was noted for all groups. The number of cases of newly diagnosed socially significant diseases (tuberculosis and HIV) also decreased. A decrease in parasitic diseases was also noted. An increase in morbidity was noted only for one item. The number of community-acquired pneumonia has increased, which is directly related to the new coronavirus infection. Many countries have implemented social distancing as a measure to "flatten the curve" of the ongoing epidemics. Evaluation of the impact of government-imposed social distancing and of other measures to control further spread of COVID-19 is urgent, especially because of the large societal and economic impact of the former.
\end{abstract}

Keywords: infectious diseases, pandemic, COVID-19, Republic of Sakha, Yakutia

\section{INTRODUCTION}

For more than a year, the world has been developing a pandemic of acute respiratory syndrome caused by the new coronavirus SARS-CoV-2. The World Health Organization called this syndrome COVID-19 from Corona Virus 2019. The starting point of the epidemic is the city Wuhan (China), where the virus was reportedly transmitted from animals to humans before transmission between people. On January 22, 2020, a meeting of the Emergency Committee was convened by the Director General of WHO in accordance with the International Health Regulations (MSMEs) (2005). The Committee took a final decision to recognize the public health emergency of international importance (PHEIC) [1]. The key strategy of the SARS-CoV-2 is to limit its transmission. Preventive measures are mainly based on the use of adequate hand hygiene and environmental disinfection measures, as well as social distancing measures aimed at limiting contacts among the population and protecting risk groups. The pandemic has raised a number of questions for health organizers around the world to identify public safety measures to prevent the collapse of health systems and reduce mortality [2]. Revision of the rules of epidemic and clinical control should concern not only patients with COVID-19 [3]. On the background of the pandemic of a new coronavirus infection, the widespread introduction of anti-epidemic measures, the situation with other infectious diseases has changed. In countries where antiepidemic measures were introduced, which were recommended by WHO, a decrease in the number of cases of infectious diseases from different groups was noted [4-6]. Norwegian researchers report that 
compared to the median of cases reported during corresponding weeks in three previous years, physicians and laboratories reported $47 \%$ fewer cases (159 vs. 301 ) in week 12, $50 \%$ fewer cases (131 vs. 261) in week 13, and $69 \%$ fewer cases (77 vs. 252) in week 14 . There was a reduction in the number of notifications of all included disease groups [7]. Australian scientists have presented a report of communicable disease surveillance in Central Queensland (CQ) for six months (1 April to 30 September 2020) after the introduction of physical distancing and wider lockdown measures in Queensland. The counts of notifiable communicable diseases in CQ in the six months were observed and compared with the average for the same months during the years 2015 to 2019. During the study's six months, there were notable decreases in notifications of most vaccine-preventable diseases such as influenza, pertussis and rotavirus. Conversely, notifications increased for disease groups such as blood-borne viruses, sexually transmitted infections and vector-borne diseases [8]. Following the outbreak of COVID-19, the Taiwan government implemented the use of masks and sanitizer, as well as other preventive measures like social distancing for prevention. This public response likely contributed significantly to the decline in the outbreak of other infectious diseases [5]. Research results suggest that information dissemination about COVID-19, which causes individual adoption of handwashing, mask-wearing, and social distancing, can be an effective strategy to mitigate and delay the epidemic [6].

The purpose of this research was to analyze the incidence of infectious diseases in the Republic of Sakha (Yakutia) during the pandemic in 2020.

\section{METHODS AND MATERIALS}

We used statistics on the incidence of infectious and parasitic diseases of the Federal Service for Supervision of Consumer Protection and Human Wellbeing. Federal Center for Hygiene and Epidemiology in Yakutia, State Report "On the State of Sanitary and Epidemiological Wellbeing of the Population in the Russian Federation" in Yakutia.

\section{RESULTS}

In Russia, the diagnosis of COVID-19 was first established in February 2020 and already in March the first case was diagnosed in Yakutia. In 2020, 24,441 cases of new coronavirus infection were registered in the republic, the incidence rate was 2531 per 100 thousand population. The largest number of cases was registered in Yakutsk, but the disease was noted in all regions of the republic. The first sharp rise in incidence was noted from 24.04.20 to 31.05.2020 - 202 cases. The largest number of cases in the weekly dynamics were observed from 46 to 51 weeks of 2020 , that is, from 30.08 .2020 to 20.12.2020. In the age structure of patients, the largest proportion was the age group of 3049 years old $-33.1 \%$, children $-13.46 \%$ of cases of new coronavirus infection.

Table 1. The incidence of COVID-19 in the Republic of Sakha (Yakutia) in 2020

\begin{tabular}{|l|l|l|l|}
\hline & $n$ & $\begin{array}{l}\text { per } 100 \text { thousand } \\
\text { population }\end{array}$ & growth \\
\hline March & 15 & 1.6 & \\
\hline April & 144 & 14.9 & +9.6 \\
\hline May & 1284 & 133 & +8.9 \\
\hline June & 2566 & 265.7 & + \\
\hline July & 1504 & 155.7 & + \\
\hline August & 1649 & 170.8 & + \\
\hline September & 1877 & 194.4 & + \\
\hline October & 3696 & 382.7 & + \\
\hline Novemder & 6450 & 667.9 & + \\
\hline December & 5256 & 544.3 & + \\
\hline
\end{tabular}

Anti-epidemic measures introduced throughout the republic, such as the transfer to the remote working regime of the maximum number of adults and distance education of schoolchildren and students, restrictions of all activities of trade, sports and entertainment institutions, the introduction of a widespread mask regime, have led to changes in the structure of infectious diseases.

The most significant changes were noted in the group of diseases transmitted by alimentary ways. Compared to the previous year, there was a $47.5 \%$ decrease in the incidence of intestinal infections in the group as a whole. The number of cases of acute enteric infections (AEI) with established pathogens decreased by $40 \%$, unidentified pathogens decreased by 2.1 times. At the present stage, the main infectious agents causing AEI are viruses. In 2020, there were no changes in the etiological structure of the AEI. Among AEI of established etiology, $82 \%$ are viral infections. At the same time, $71.9 \%$ of cases of AEI of viral etiology occur in rotavirus infection. The incidence of viral intestinal infections decreased by $41.9 \%$ compared to last year. A total of 581 cases of rotavirus infection were recorded, the index per 100 thousand population was 59.93. The incidence of rotavirus infection decreased by $25.7 \%$ compared to 2019 . In 2020, there was a decrease in the incidence, also norovirus infection by 2.1 times. The incidence of acute intestinal infections of bacterial etiology in 2020 compared to the previous year decreased by $29 \%$. A total of 146 cases were registered, the index is 18.15 per 100 thousand population. In 2020, 15 cases of viral hepatitis $\mathrm{A}$ were registered, the 
incidence rate was 1.55 per 100 thousand of the population, which is $11.9 \%$ lower than last year.

Table 2. The incidence rates of intestinal infections per 100 thousand population 2016-2020

\begin{tabular}{|l|l|l|l|l|l|}
\hline & 2016 & 2017 & 2018 & 2019 & 2020 \\
\hline $\begin{array}{l}\text { Salmonella } \\
\text { infections }\end{array}$ & 45.2 & 28.2 & 41.7 & 62.65 & 34.4 \\
\hline $\begin{array}{l}\text { Bacterial } \\
\text { dysentery }\end{array}$ & 2.19 & 2.9 & 4.36 & 2.69 & 0.21 \\
\hline $\begin{array}{l}\text { AEl of } \\
\text { established } \\
\text { etiology }\end{array}$ & 142.9 & 161.1 & 172.1 & 168.9 & 101.4 \\
\hline $\begin{array}{l}\text { AEl of } \\
\text { unknown } \\
\text { etiology }\end{array}$ & 281.2 & 262.5 & 317.8 & 277.6 & 132.5 \\
\hline $\begin{array}{l}\text { Viral } \\
\text { hepatitis A }\end{array}$ & 0.94 & 3.5 & 3.22 & 1.76 & 1.55 \\
\hline
\end{tabular}

In 2020, on the background of restrictive measures related to the coronavirus infection pandemic in the Republic of Sakha (Yakutia) there was a multiple decrease in the incidence of enterovirus infections (EVI) - 9.1 times compared to 2019. Perhaps this is due to the fact that enterovirus infection has both an alimentary mechanism of transmission of infection and air infection.

In 2020, the incidence of enterovirus infections is recorded only among children under 14 years of age, the incidence rate is 11.36 per100 thousand children (in $2019-98.79 \%$ ).

Table 3. The age structure of the incidence of EVI in children under old was

\begin{tabular}{|l|l|l|l|l|}
\hline & $\begin{array}{c}0-1 \\
\text { year }\end{array}$ & $\begin{array}{l}1-2 \text { years } \\
\text { old }\end{array}$ & $\begin{array}{l}3-6 \\
\text { years old }\end{array}$ & $\begin{array}{l}7-14 \text { years } \\
\text { old }\end{array}$ \\
\hline EVI & $13 \%$ & $37 \%$ & $20 \%$ & $30 \%$ \\
\hline
\end{tabular}

On the background of COVID-19 pandemic also a decrease in incidence of acute respiratory infections is noted. Acute respiratory viral infections (SARS) and influenza have always been and remain one of the most pressing health issues. In 2020, the etiological structure of influenza was dominated by influenza virus type A (H1N1) pdm09-89.9 \%, B - 9.2\%, A (H3N2)- $1.0 \%$. Among non-influenza viruses, parainfluenza amounted to $46.1 \%, 21.2 \%$ - adenoviruses, $7.3 \%$ - RS-infection viruses, $14.6 \%$ - other respiratory viruses. In 2020 , the incidence rate of SARS per 100 thousand population decreased by $19.6 \%$ compared to last year. Moreover, among children under the age of 17 , the decrease was even greater - by $41.6 \%$. In 2020, 142 laboratory confirmed cases of influenza were registered (in 2019 645 cases), including 42 cases (29.6\% of all cases) among children under 17 years old. The incidence rate among the total population was 4.6 times lower than in the previous year. The incidence rate among children under 17 years old amounted to 15.9 per 100 thousand children's population, which is 6 times lower than in 2019.

Table 4. The etiological structure of respiratory viruses based on the results of rapid diagnostics in the virology laboratory "Center for Hygiene and Epidemiology" (n)

\begin{tabular}{|l|l|l|l|l|l|}
\hline & 2016 & 2017 & 2018 & 2019 & 2020 \\
\hline $\begin{array}{l}\text { Influenza virus } \\
\text { type A }\end{array}$ & 292 & 71 & 27 & 246 & 121 \\
\hline $\begin{array}{l}\text { Influenza virus } \\
\text { type B }\end{array}$ & 0 & 82 & 1 & 8 & 0 \\
\hline Adenoviruses & 208 & 121 & 294 & 415 & 387 \\
\hline $\begin{array}{l}\text { RS-infection } \\
\text { viruses }\end{array}$ & 98 & 95 & 276 & 80 & 134 \\
\hline $\begin{array}{l}\text { Other } \\
\text { respiratory } \\
\text { viruses }\end{array}$ & 8 & 2 & 17 & 11 & 159 \\
\hline
\end{tabular}

Influenza vaccination plays a role in reducing the incidence of influenza. On the eve of the epidemic season of influenza in 2020, 604619 people were vaccinated against influenza in the republic, which is $62.4 \%$ of the total population, including 583603 people (60.2\% of the population) were vaccinated at the expense of the federal budget, of them 220,810 children were vaccinated ( $83.6 \%$ of the child population).

Analyzing the incidence of controlled infections in 2020, it should be noted that in January 2020, the measles outbreak continued in the Republic of Sakha (Yakutia), which began in December 2019. The total number of cases of 68 people (in December 2019 - 40 cases, in January 2020 - 28 cases), all cases are laboratory confirmed. The measles outbreak began in December 2019, and continued for three incubation periods. Given this situation, the incidence of measles in 2020 turned out to be higher than in previous years, with the exception of 2015. In 2015, there was an epidemic rise in the incidence of measles, when 37 laboratory confirmed cases of the disease were recorded. The index per 100 thousand people in 2006 to 2018 ranged from 0 to 0.8 , in 2020 it amounted to 2.99 per 100 thousand people.

In 2020, not a single case of rubella, diphtheria, 1 case of mumps was recorded in Yakutia. For all these nosological cases, a prosperous epidemiological situation has been observed in the republic for several years. A decrease in morbidity was noted for whooping 
cough. In total, 10 cases of whooping cough among the population were recorded in 2020 year, the incidence rate was 1.03 per 100 thousand of the population, which is 3.9 times lower than the incidence rate of 2019 year.

Table 5. The incidence of measles in the population of Yakutia 2016-2020

\begin{tabular}{|l|l|l|l|l|l|}
\hline & 2016 & 2017 & 2018 & 2019 & 2020 \\
\hline Russian & 0.11 & 0.5 & 1.78 & 3.05 & 0.83 \\
\hline Yakutia & 0 & 0 & 0.1 & 4.14 & 2.9 \\
\hline
\end{tabular}

Table 6. The incidence of whooping cough in the population of Yakutia 2016-2020

\begin{tabular}{|l|l|l|l|l|l|}
\hline & 2016 & 2017 & 2018 & 2019 & 2020 \\
\hline Russian & 5.63 & 3.7 & 7.1 & 9.8 & 4.13 \\
\hline Yakutia & 4.7 & 11.03 & 11 & 4.04 & 1.03 \\
\hline
\end{tabular}

When analyzing the incidence of controlled infections, it is necessary to take into account of vaccinated population.

Table 6 shows the timeliness of preventive vaccinations at the age of 24 months.

Table 7. Coverage of preventive vaccinations in Yakutia

\begin{tabular}{|l|l|l|l|}
\hline Diseases & 2018 & 2019 & 2020 \\
\hline Measles & 96.3 & 91.5 & 98.6 \\
\hline Rubella & 98.7 & 98.4 & 98.6 \\
\hline Epidemic parothitis & 98.7 & 98.4 & 98.6 \\
\hline Diphtheria & 97.4 & 96.7 & 96.6 \\
\hline Whooping cough & 97.3 & 96.6 & 96.6 \\
\hline
\end{tabular}

Table 7 shows that during the pandemic period there was no decrease in the vaccination rate of the child population. Together with wide anti-epidemic measures, this gave a positive result. The number of measles vaccines increased compared to the last year, as a result of anti-epidemic interventions related to the measles outbreak.

A significant decrease in the number of varicella cases is directly related to the introduction of restrictive measures and maximum separation of working groups. In Yakutia in 2020, 3,102 cases of chickenpox were registered (the indicator was 320.0 per 100 thousand population), which is $36.8 \%$ lower than the incidence rate of 2019 (in $2019-506.0$ ).

Among children under 14 years of age, 29 cases or 12.8 per 100 thousand children under 14 years of age were registered, which is 1.1 times lower than the level of 2019.
Table 8. The incidence of varicella in the population of Yakutia 2016-2020

\begin{tabular}{|l|l|l|l|l|l|}
\hline & 2016 & 2017 & 2018 & 2019 & 2020 \\
\hline Russian & 543.84 & 585.21 & 571.22 & 558.8 & 333.76 \\
\hline Yakutia & 743.3 & 663.7 & 748 & 506 & 320 \\
\hline
\end{tabular}

There was also a decrease in the number of cases of streptococcal infection by $39.2 \%$, infectious mononucleosis - by 3.6 times.

In recent years, Yakutia has had a low incidence of viral hepatitis. In 2020, 24 cases of acute viral hepatitis were registered in the Republic of Sakha (Yakutia), the incidence rate was 2.48 per 100 thousand population, which is $20.3 \%$ lower than in 2019 (3.11 per 100 thousand population). The decrease in the incidence rate of acute viral hepatitis is due to a decrease in the incidence of viral hepatitis A by 1.1 times, viral hepatitis $\mathrm{B}$ by 1.9 times and viral hepatitis $\mathrm{C}$ by 1.6 times.

The main epidemiological indicators for tuberculosis in Yakutia for many years, have a steady downward trend, but in comparison with the average Russian indicators they continue to remain at a high level. The decrease in the number of cases of the first detected tuberculosis decreased by $37.6 \%$, and cases of respiratory tuberculosis by $39 \%$, compared to 2019 .

Table shows the incidence of active tuberculosis.

Table 9. The incidence of active tuberculosis per 100 thousand population

\begin{tabular}{|l|l|l|l|}
\hline & 2018 & 2019 & 2020 \\
\hline Russian & 41.95 & 38.62 & 29.8 \\
\hline Far East & 78.29 & 85.05 & 50.5 \\
\hline Yakutia & 54.38 & 50.43 & 31.5 \\
\hline
\end{tabular}

In Yakutia the situation with the incidence of HIV infection remains tense. The incidence rate of HIV infection in 2020 was 13.7 per 100 thousand people, which is $25.2 \%$ lower than in 2019. However, it should be noted a decrease in preventive examination (screening) of the population of the republic in connection with the measures taken to counter the spread of new coronavirus infection (COVID-19). A similar situation is common throughout the country. Nevertheless, despite the decrease in screening coverage, the detection rate of HIV infection per 100,000 examinations, among citizens of the Russian Federation, in 2020 (65.2) remains at the level of 2019 (62.1). The average republic indicator was 2.4 times lower than in the Far Eastern Federal District and 2.9 times lower than in the Russian Federation. 
Table 10. The incidence of HIV infection per 100 thousand population

\begin{tabular}{|l|l|l|l|}
\hline & 2018 & 2019 & 2020 \\
\hline Russian & 58.9 & 62.1 & 65.2 \\
\hline Yakutia & 15.8 & 18.3 & 13.7 \\
\hline
\end{tabular}

In the republic, the most common parasitic diseases are lambliosis, enterobiosis and diphyllobotriosis. A decrease in incidence in 2020 was noted for all these diseases, on average by $42.7 \%$.

Only one position showed an increase in morbidity. The number of community-acquired pneumonia (CAP) has increased. A similar picture was observed in Russia and in the Far Eastern Federal District.

Table 11. The incidence of community-acquired pneumonia per 100 thousand population

\begin{tabular}{|l|l|l|}
\hline & 2019 & 2020 \\
\hline Russian & 517.61 & 1854.04 \\
\hline Far East & 1153.49 & 1901 \\
\hline Yakutia & 777.03 & 1613.5 \\
\hline
\end{tabular}

In 2020, in Yakutia, the number of CAP increased 2.1 times. At the same time, the number of cases of clarified etiology decreased: bacterial pneumonia 2.2 times, pneumococcal etiology $49.9 \%$. The share of CAP of unspecified etiology reached $72 \%$. Analysis of the etiological structure of the incidence of communityacquired pneumonia in the Republic of Sakha (Yakutia) in 2020 showed that the overwhelming majority of cases $18.0 \%$ were caused by bacterial agents (2019 $10.6 \%$ ). Viral etiology was detected in $10.0 \%$ of cases $(2019-8.3 \%)$. The maximum decrease in bacterial pneumonia, including pneumococcal, was noted among children, 3.9 times and 2.4 times, respectively. The maximum incidence rate of CAP was observed for the age group over 65 years (4459.2 per 100 thousand population of this age group). The mortality rate for CAP also increased. In 2020, the annual dynamics of out-of-hospital pneumonia was characterized by summer (June-July) and autumn-winter (SeptemberDecember) seasons. The maximum season incidence rate is December. Which corresponds to the dynamics of the increase in the incidence of COVID-19.

\section{CONCLUSIONS}

Thus, we can argue that the introduction of antiepidemic measures, on the background of a new coronavirus infection, led to a significant decrease in infectious morbidity in general. For infectious diseases transmitted by usual ways and air, a similar situation was expected. However, there has been a decrease in those infectious diseases for which a direct correlation between anti-epidemic interventions such as mask regimen, social distance and self-isolation regimen and the incidence of these pathologies is not apparent. These include viral hepatitis with parenteral transmission of the virus, parasitic diseases such as diphyllobotriosis. It should also be noted that earlier introduction of antiepidemic measures was carried out, for example, with an increase of influenza cases, but it could not help to achieve significant results. The 2020 situation shows that the effectiveness of anti-epidemic work is directly related to the mass and wide coverage of measures.

\section{REFERENCES}

[1] WHO Director-General's statement on IHR Emergency Committee on Novel Coronavirus (2019-nCoV), World Health Organization (WHO), Geneva, 2020.

[2] E.M.L. Aquino, I.H. Silveira, J.M. Pescarini et al., Ciência \& Saúde 25 (2020) 2423-2446.

[3] A. Hassoun, N. Prasad, S. Pugh et al., J. Pediatric. Infect. Dis. Soc. 9(5) (2020) 564-565.

[4] A.M. Sadeghi, Med. Hypotheses. 146 (2021) 11045.

[5] C.J. Galvin, Yu-Ch.J. Li, Sh. Malwade et al., Int. J. Infect. Dis. 98 (2020) 18-20.

[6] A. Teslya, Th.M. Pham, N.G. Godijk et al., PLoS Med. 17(7) (2020) 1003166.

[7] P. Stefanoff, A.L. Løvlie, P. Elstrøm, E.A. Macdonald, Tidsskr. den Nor. Laegeforen. 15 (2020) 140 .

[8] O. Adegbija, J. Walker, N. Smoll et al., Commun. Dis. Intell. 45 (2021). 